Check for updates

Cite this: RSC Adv., 2018, 8, 33882

Received 25th July 2018

Accepted 25th September 2018

DOI: $10.1039 / c 8 r a 06281 a$

rsc.li/rsc-advances

\section{Characterization and osteogenic evaluation of mesoporous magnesium-calcium silicate/ polycaprolactone/polybutylene succinate composite scaffolds fabricated by rapid prototyping}

\author{
Yun Gyeong Kang, (DD a Jie Wei, ${ }^{\text {b }}$ Ji Eun Kim, ${ }^{a}$ Yan Ru Wu, ${ }^{c}$ Eun Jin Lee, ${ }^{\text {a }}$ Jiacan Su (D) d \\ and Jung-Woog Shin (iD *ace
}

The properties of scaffolds for bone tissue engineering, including their biocompatibility, highly interconnected porosity, and mechanical integrity, are critical for promoting cell adhesion, proliferation, and osteoinduction. We used various physical and biological assays to obtain in vitro confirmation that the proposed composite scaffolds are potentially suitable for applications to bone tissue engineering. The proposed new composite scaffolds, which we fabricated by a rapid prototyping technique, were composed of mesoporous magnesium-calcium silicate (m_MCS), polycaprolactone (PCL), and polybutylene succinate (PBSu). We systematically evaluated the characteristics of the composite scaffolds, such as the hydrophilicity and bioactivity. We also investigated the proliferation and osteogenic differentiation of human mesenchymal stem cells (MSCs) scaffolded on the m_MCS/PCL/PBSu composite. Our results showed that, compared to the $\mathrm{m}_{-} \mathrm{MCS} / \mathrm{PCL}$ scaffold, the $\mathrm{m} \_\mathrm{MCS} / \mathrm{PCL} / \mathrm{PBS}$ u scaffold has improved water absorption, in vitro degradability, biocompatibility, and bioactivity in simulated body fluid, while its mechanical strength is reduced. Moreover, the results of the cytotoxicity tests specified in ISO 10993-12 and ISO 10993-5 clearly indicate that the m_MCS/PCL scaffold is not toxic to cells. In addition, we obtained significant increases in initial cell attachment and improvements to the osteogenic MSC differentiation by replacing the $\mathrm{m}_{-} \mathrm{MCS} / \mathrm{PCL}$ scaffold with the $\mathrm{m} \_\mathrm{MCS} / \mathrm{PCL} / \mathrm{PBS}$ u scaffold. Our results indicate that the $\mathrm{m}_{-} M C S / P C L / P B S u$ scaffold achieves enhanced bioactivity, degradability, cytocompatibility, and osteogenesis. As such, this scaffold is a potentially promising candidate for use in stem cell-based bone tissue engineering.

\section{Introduction}

Bone grafts have been used extensively to treat various bone defects and disorders. ${ }^{1,2}$ However, our ability to offer treatments based on autografts is hindered by several obstacles, such as the limited availability of donor material, risk of donor-site morbidity, ${ }^{3}$ unsolved problems due to minor immunogenic rejection and the risk of disease transmission. ${ }^{4}$ Therefore,

${ }^{a}$ School of Biomedical Engineering, Inje University, Rm \#309, BLDG-A, 197, Inje-ro, Gimhae, Gyeongsangnam-do, 50834, Republic of Korea. E-mail: biomechshin@ gmail.com; Fax: +82-55-327-3292; Tel: +82-55-320-3317

${ }^{b}$ Key Laboratory for Ultrafine Materials of Ministry of Education, East China University of Science and Technology, Shanghai, China

'Department of Health Science and Technology, Inje University, Gimhae, Gyeongsangnam-do, Republic of Korea

${ }^{d}$ Department of Orthopaedics, Changhai Hospital, Second Military Medical University, Shanghai, China

${ }^{e}$ Cardiovascular and Metabolic Disease Center/Institute of Aged Life Redesign/UHARC, Inje University, Gimhae, Republic of Korea scaffold-based bone tissue engineering techniques have attracted attention from clinicians as a potential alternative treatment. Ideally, scaffolds should not only provide a threedimensional (3D) microenvironment with adequate physical, chemical and mechanical properties, they should also modulate bone regeneration by stimulating cell proliferation, differentiation, migration, and extracellular matrix (ECM) formation..$^{5-7}$

Multiple attempts have been made to obtain the desired porosity and mechanical properties by fabricating scaffolds composed of a range of materials, such as inorganic bioactive ceramics, glass or biodegradable polymers. ${ }^{6,8}$ Polycaprolactone (PCL) has been widely used in bone tissue engineering due to its excellent drug permeability, solubility, biocompatibility, and ability to maintain its mechanical and physical properties. However, PCL is not sufficiently wettable and has a hydrophobic surface, which causes interference in cell adhesion and integration. ${ }^{9,10}$ Polybutylene succinate (PBSu) is not just a biodegradable polymer with nontoxic degradation products $\left(\mathrm{C}_{2} \mathrm{O}\right.$ and $\left.\mathrm{H}_{2} \mathrm{O}\right),{ }^{11}$ it is also easier to process than poly(lactic acid) and 
poly(glycolic acid), and has excellent mechanical properties for bone tissue engineering, hydrophilicity that is adequate for facilitating cell attachment, and an adjustable degradation rate. ${ }^{12-14}$ However, the osteocompatibility of PBSu is limited, tending not to provide sufficient osteogenesis after transplantation. $^{\text {12,15 }}$ Hence, it is essential that we improve the osteocompatibility of PBSu before it can be used as a bone substitute.

Various methods have been developed to overcome the limitations associated with biodegradable polymers and promote osteogenesis and osseointegration with living bones, such as bioactive coating, physical modifications, and developing composites by blending with other materials with bioactive properties, such as bioglass, bioactive calcium phosphate ceramics, and hydroxyapatite. ${ }^{\mathbf{1 6 - 1 9}} \mathrm{Li}$ et al. reported that using scaffolds composed of PCL and mesoporous bioactive glasses (MBGs) instead of conventional bioglass composites, yields enhanced hydrophilicity and bioactivity. ${ }^{20}$ Zhu et al. confirmed that cerium-incorporated mesoporous calciumsilicate scaffolds induced similar apatite deposition, enhanced cell attachment and osteogenic differentiation. ${ }^{21}$ Moreover, previous studies have confirmed that MBGs can stimulate cell adhesion, proliferation, and differentiation into osteoblast (OB)-like cells, thus introducing new bone ingrowth into the scaffold. ${ }^{22-25}$ Among MBG, namely mesoporous magnesiumcalcium silicate bioglass (m_MCS), has a large surface area and high porosity, and exhibits excellent biocompatibility and bioactivity. ${ }^{26,27} \mathrm{Lu}$ et al. found that m_MCSs stimulates new bone formation and osteointegration by inducing the deposition of apatite onto its surface. ${ }^{26}$

The specific manufacturing technique used to fabricate a scaffold for bone tissue engineering is as important as the choice of materials. ${ }^{28}$ Conventional techniques for fabricating scaffolds, such as salt leaching, phase separation and freeze drying, do not allow for precise control of the size, geometry, or interconnectivity of the pores. These limitations do not arise when using rapid prototyping (RP) techniques, which produce organized 3D structures using computer assisted design/computer assisted manufacturing (CAD/CAM) systems. Hence, these techniques have recently attracted a lot of attention. RP technique is a good method for designing and fabricating customized structures. ${ }^{29}$

Herein, we propose a novel porous scaffold composed of m_MCS, PCL, and PBSu that can be fabricated by RP technique. We performed a number of analyses to characterize the materials used in the proposed scaffolds and their mechanical properties. Further, we demonstrated the cytocompatibility of the novel m_MCS/PCL/PBSu composite scaffolds by investigating cell proliferation and osteogenic differentiation using human mesenchymal stem cells (MSCs). These results suggest that they are potentially suitable for applications to stem cellbased bone tissue engineering.

\section{Material and methods}

\section{Preparation of scaffolds}

We obtained m_MCS powders, which were synthesized by template methods, from the East China University of Science and Technology (Shanghai, China), ${ }^{30}$ and purchased PCL $\left(M_{\mathrm{W}}\right.$ 43000-50000) and PBSu from Polyscience, Inc. (Warrington, PA, USA) and Shanghai Showa Highpolymer Co. Ltd (Shanghai, China), respectively.

We prepared the $\mathrm{m} \_\mathrm{MCS} / \mathrm{PCL}$ and $\mathrm{m} \_\mathrm{MCS} / \mathrm{PCL} / \mathrm{PBSu}$ composites by mixing their constituents at $115{ }^{\circ} \mathrm{C}$ until we obtained a homogeneous substance. The weight ratios of the components of the proposed scaffolds were as follows: (1) m_MCS/PCL (m_MCS : PCL = $20: 80$ weight per weight; w/w); (2) $\mathrm{m} \_\mathrm{MCS} / \mathrm{PCL} / \mathrm{PBSu}\left(\mathrm{m} \_\mathrm{MCS}: \mathrm{PCL}: \mathrm{PBSu}=20: 50: 30 \mathrm{w} /\right.$ w). Each scaffold was fabricated using a 3D plotting system (M4T, Korea). Each composite was placed inside the heating cylinder and heated electrically to $115{ }^{\circ} \mathrm{C}$. The melted solution was then extruded through a nozzle with diameter $350 \mu \mathrm{m}$ under $680 \mathrm{kPa}$ pressure. We analyzed the surfaces of the fabricated scaffolds, which were sputter-coated with Au, under a scanning electron microscope (SEM) (S3500N; Hitachi, Tokyo, Japan), and characterized their phase compositions by X-ray diffraction (XRD) (Empyrean series 2; PANalytical, Almelo, The Netherlands) with a scan range from $10^{\circ}$ to $60^{\circ}$.

\section{Hydrophilicity and mechanical characterization}

We evaluated the hydrophilicity of each scaffold by measuring its contact angle using a contact angle analyzer (Phoenix 250; Surface \& Electro Optics, Gyeonggi-do, Korea) and Image Pro 300 software (Surface \& Electro Optics). Briefly, for each sample, we dropped water droplets at three different locations, then, 60 seconds later, we measured the contact angles between each droplet and the surface of the sample.

We conducted compression tests using a Micro-load System (R \& B Inc., Daejeon, Korea) equipped with a $10 \mathrm{kN}$ load cell at room temperature ( $n=5$ for each group). We cut each fabricated scaffold to dimensions of $6 \times 6 \times 5.5 \mathrm{~mm}^{3}$, set the displacement rate to $1 \mathrm{~mm} \mathrm{~min}^{-1}$, then used the data obtained to calculate the compressive modulus.

\section{Water absorption and in vitro degradability}

The water absorption of $\mathrm{m} \_\mathrm{MCS} / \mathrm{PCL}$ and $\mathrm{m} \_\mathrm{MCS} / \mathrm{PCL} / \mathrm{PBSu}$ scaffolds were evaluated by measuring the weight gain after the samples were soaked in Dulbecco's phosphate buffered saline solution (DPBS; $\mathrm{pH}=7.4$ ) for different times. Briefly, the scaffolds $\left(6 \times 6 \times 5.5 \mathrm{~mm}^{3} ; n=5\right)$ were weighed and then immersed into DPBS. At the predetermined time points, the samples were taken out from DPBS, and the weight of the samples were measured. The water absorption ratio of the samples at different time points was determined by the following equation: water absorption ratio $(\%)=\left(W_{\mathrm{w}}-W_{0}\right) / W_{0}$ $\times 100$, where $W_{0}$ is the initial weight and $W_{\mathrm{w}}$ is the wet sample weight.

To confirm in vitro degradability of the m_MCS/PCL and m_MCS/PCL/PBSu scaffolds, weight loss ratio of the sample was measured. Briefly, each scaffold $\left(6 \times 6 \times 5.5 \mathrm{~mm}^{3} ; n=5\right)$ was weighed $\left(W_{0}\right)$ and then soaked in DPBS ( $\mathrm{pH}$ 7.4) using a shaking water bath at $37^{\circ} \mathrm{C}$. At the specified measurement times $(1,3,7$, 14,21 and 28 days), the scaffolds were taken outs, dried at $55^{\circ} \mathrm{C}$ for 24 hours, and weighed again $\left(W_{\mathrm{d}}\right)$. This test was performed 
up to 28 days. The weight loss ratio of the samples was calculated as follows: weight loss ratio $(\%)=\left(W_{0}-W_{\mathrm{d}}\right) / W_{0} \times 100$. The $\mathrm{pH}$ value of DPBS solution $(n=5)$ after the scaffolds were immersed for different times was checked by using a $\mathrm{pH}$ meter (Thermo Fisher Scientific, Waltham, MA).

\section{In vitro bioactivity in simulated body fluid}

The in vitro bioactivity of each scaffold was determined by soaking them in simulated body fluid (SBF), which we prepared according to the methods developed by Kokubo and Takadama. ${ }^{31}$ The scaffolds were soaked in SBF in a shaking water bath at $37{ }^{\circ} \mathrm{C}$ for 10 days and had a solution volume/specimen weight ratio of $20 \mathrm{ml} \mathrm{g}^{-1}$. We used inductively coupled plasma optical emission spectrometry (ICP-OES) (Optima 4300 DV; PerkinElmer, Shelton, CT, USA) to measure the differences between the ion concentrations ( $\mathrm{Ca}, \mathrm{P}, \mathrm{Mg}$ and $\mathrm{Si}$ ) in the $\mathrm{SBF}$ after immersing the scaffolds for different lengths of time: 0,1 , $3,5,7$ and 10 days.

\section{Cytotoxicity test}

Before the cytotoxicity tests, we sterilized each scaffold $(6 \times 6 \times$ $5.5 \mathrm{~mm}^{3}$ ) in $70 \%$ ethanol for 3 hours, then immersed them in deionized water (D.W) and irradiated them with UV radiation for 30 minutes. Each scaffold was immersed in culture medium (100 mg ml $\mathrm{ml}^{-1}$ ) consisting of Dulbecco's modified Eagle's medium (DMEM; Thermo Fisher Scientific) supplemented with 10\% fetal bovine serum (FBS; Thermo Fisher Scientific), $100 \mathrm{U}$ $\mathrm{mL}^{-1}$ penicillin (Thermo Fisher Scientific), and $100 \mathrm{mg} \mathrm{ml}$ streptomycin (Thermo Fisher Scientific) at $37^{\circ} \mathrm{C}$ for 24 hours, at which time we collected the resulting extracts. Phenol (1\%), PCL and DMEM were used as the positive and negative controls, respectively.

We seeded mouse fibroblast-like cells (L929 cells; Korean Cell Line Bank, Seoul, Korea) in a 48 -well culture plate $\left(5 \times 10^{4}\right.$ cells per $\mathrm{cm}^{2}$ ) and cultured them with each extract for 24 hours. The viable cells were quantified by a 3-(4,5-dimethylthiazol-2-yl)2,5-diphenyl-tetrazolium bromide (MTT; Roche Applied Science, Indianapolis, IN, USA) assay, which we performed as follows. MTT labeling reagent was added to each well and the plates were incubated for 4 hours at $37{ }^{\circ} \mathrm{C}$; we then added solubilization solution to each well and incubated the samples overnight at $37{ }^{\circ} \mathrm{C}$. The optical density (O.D.) of each well was measured at $570 \mathrm{~nm}$ in a microplate reader (Multiskan EX; Thermo Fisher Scientific).

\section{MSC seeding and culture}

Prior to seeding the MSCs on the scaffold, we sterilized them as described above, then treated them with $10 \mu \mathrm{g} \mathrm{ml}^{-1}$ fibronectin (Sigma-Aldrich, St. Louis, MO, USA) in DPBS for 2 hours to promote cell attachment.

We purchased human bone marrow-derived MSCs from Lonza (Walkersville, MD, USA), which we cultured by following the manufacturer's protocol up to passage \#4, and then seeded onto each fibronectin-coated scaffold at a concentration of $1 \times$ $10^{6}$ cells per $\mathrm{ml}$ by applying an infiltration method. We induced the MSCs to begin osteogenic differentiation in DMEM with low glucose (Thermo Fisher Scientific) containing $50 \mu \mathrm{g} \mathrm{ml}{ }^{-1} \mathrm{~L}^{-}$ ascorbic acid (Sigma-Aldrich), $10 \mathrm{mM} \quad \beta$-glycerophosphate (Sigma-Aldrich), $10^{-7} \mathrm{M}$ dexamethasone (Sigma-Aldrich), 10\% FBS (Thermo Fisher Scientific), $100 \mathrm{U} \mathrm{mL}^{-1}$ penicillin (Thermo Fisher Scientific), and $100 \mathrm{mg} \mathrm{mL}{ }^{-1}$ streptomycin (Thermo Fisher Scientific).

\section{Morphology and viability of the MSCs}

We characterized the morphologies of the MSCs on the scaffolds by imaging with an SEM (Hitachi, Tokyo, Japan). After culturing the scaffold-cell constructs for 7 days, we fixed them with $10 \%$ formalin for 10 minutes. The samples were dehydrated for 5 minutes at each concentration of a graded ethanol series (50, 60, 70, 80, 90, and 100\% volume/volume; v/v) and then air-dried in a desiccator overnight. The dried samples were sputter-coated with Au prior to the SEM observations.

We observed the cytoskeletal arrangement of the MSCs by staining them with filamentous actin (F-actin) with tetramethylrhodamine (TRITC)-labeled phalloidin (Sigma-Aldrich) on day 7 . The cell-scaffold constructs were fixed in $10 \%$ formalin, permeabilized with $0.1 \%$ Triton $\mathrm{X}-100$, then reacted with phalloidin-TRITC in DPBS $\left(2 \mu \mathrm{g} \mathrm{ml}^{-1}\right)$ for 20 minutes in the dark. We mounted samples with Vectashield containing 4',6diamidino-2-phenylindol (DAPI); (Vector Laboratories, Burlingame, CA, USA), then finally observed the stained cells using a confocal laser scanning microscope (LSM 510 META; Carl Zeiss, Jena, Germany).

On day 7 , we performed a live/dead viability assay (Thermo Fisher Scientific) by following the manufacturer's instructions. We pipetted a $1 \mathrm{ml}$ aliquot of the assay solution containing $2 \mu \mathrm{l}$ EthD-1 (ethidium homodimer-1) and $0.5 \mu \mathrm{l}$ calcein AM onto each cell-scaffold construct, then incubated them at room temperature for 30 minutes. The stained cells were observed using a confocal laser scanning microscope (Carl Zeiss) with excitation/emission filters set to $488 / 530 \mathrm{~nm}$ and 530/580 $\mathrm{nm}$ to observe, respectively, the alive (green) and dead (red) cells.

\section{MSC proliferation}

We evaluated the proliferation of MSCs by measuring the DNA content using a Quanti-iT PicoGreen dsDNA Kit (Thermo Fisher Scientific). The PicoGreen dye bound to the nucleic acids, enabling us to determine the DNA concentrations by measuring the fluorescence activity. Triton X-100 (0.1\%) was added to the samples, which we then centrifuged at $13000 \mathrm{rpm}$ for 5 minutes at $4{ }^{\circ} \mathrm{C}$. The PicoGreen reagent was added to all 96-well plates, and the samples were then incubated in the dark for 5 minutes. The fluorescence emission intensity was measured at $520 \mathrm{~nm}$ using a multi-detection microplate reader (Synergy HT; BioTek instruments, Winooski, VT, USA).

\section{Alkaline phosphatase (ALP) activity}

We assessed the early cell differentiation by measuring the alkaline phosphatase (ALP) activity. Triton X-100 (0.1\%) was added to the samples, followed by centrifugation at $13000 \mathrm{rpm}$ for 5 minutes at $4{ }^{\circ} \mathrm{C}$. We added the substrate (Sigma-Aldrich) and alkaline buffer (Sigma-Aldrich) solutions to each sample 
Table 1 Primers used for quantitative real-time polymerase chain reaction

Forward (F) and reverse (R) primer

\begin{tabular}{|c|c|c|}
\hline Gene & $\left(5^{\prime} \rightarrow 3^{\prime}\right)$ & Accession no. \\
\hline \multirow[t]{2}{*}{ RUNX2 } & (F) TGAGATTTGTGGGCCGGAGTGG & \multirow[t]{2}{*}{ NM_001024630. } \\
\hline & (R) TCTGTGCCTTCTGGGTTCCCGA & \\
\hline \multirow[t]{2}{*}{ BSP } & (F) CAGAGGCAGAAAACGGCAAC & \multirow[t]{2}{*}{ NM_004967.3 } \\
\hline & (R) TTGTTGTCTTCGAGGTGCCC & \\
\hline \multirow[t]{2}{*}{ OPN } & (F) GGAAAGCGAGGAGTTGAATGGTGC & \multirow[t]{2}{*}{ NM_000582.2 } \\
\hline & (R) GGACTGCTTGTGGCTGTGGGTTTC & \\
\hline \multirow[t]{2}{*}{ ACTB } & (F)CCAAAGTTCACAATGTGGC & \multirow[t]{2}{*}{ NM_001101.3 } \\
\hline & (R) GATGGCAAGGGACTTCCTGT & \\
\hline
\end{tabular}

at $37{ }^{\circ} \mathrm{C}$ for 30 minutes. After the reaction stopped, $1 \mathrm{~N} \mathrm{NaOH}$ solution was added to each sample. The samples were then transferred into 96-well plates, and the absorbance at $405 \mathrm{~nm}$ was measured using a microplate reader (Multiskan EX; Thermo Fisher Scientific).

\section{Quantitative real-time polymerase chain reaction (qRT-PCR)}

We conducted quantitative real-time polymerase chain reaction (qRT-PCR) to detect the expression of bone-related genes, such as runt related transcription factor 2 (RUNX2), bone sialoprotein (BSP), and osteopontin (OPN) in the MSCs (Table 1). We used an internal housekeeping gene called actin beta (ACTB) as a control. The total RNA was purified using an RNeasy Mini Kit (Qiagen, Hilden, Germany) according to the manufacturer's instructions, followed by preincubation of the resulting RNA with DNase I (Thermo Fisher Scientific). We applied the manufacturer's instructions to perform reverse transcription with a high-capacity RNA to cDNA kit (Thermo Fisher Scientific). The qRT-PCR was performed on the cDNA using a Power SYBR Green PCR Master Mix (Thermo Fisher Scientific). We applied the $2^{-\Delta \Delta C_{\mathrm{t}}}$ method on a QuantStudio 3 Real-Time PCR System (Thermo Fisher Scientific) to perform the data analysis. The qRT-PCR analysis of each sample was performed three times. We then compared the gene expression levels using MSCs (primary cells) as the negative control and human OBs as the positive control.

\section{Statistical analyses}

We determined whether the data sets were significantly different by conducting a one-way analysis of variance (ANOVA) test using PASW Statistics software (ver. 23.0; SPSS Inc., Chicago, IL, USA). We then applied the least-significant difference (LSD) test to evaluate which of the groups identified by the ANOVA test were significantly different. All data are presented as means \pm standard deviation (SD), with $p<0.05$ taken to indicate significance.

\section{Results and discussion}

\section{Characterization of $\mathbf{m} \_$MCS/PCL/PBSu scaffold}

The photographs of the m_MCS/PCL and m_MCS/PCL/PBSu scaffolds fabricated by the RP technique show that the
m_MCS/PCL/PBSu scaffolds are similar to the m_MCS/PCL scaffolds, with uniformly distributed, well-interconnected pores (Fig. 1A). The drawbacks of the conventional particulate leaching, gas foaming and freeze drying techniques, such as the difficulty of controlling the pore size, geometry, and interconnectivity, can be overcome by RP techniques. ${ }^{29,32}$ The SEM images (Fig. 1B) show that each scaffold has rectangular pores, with heights $<600 \mu \mathrm{m}$ and widths $<300 \mu \mathrm{m}$. The structures of the pore play a critical role in cell growth, nutrient flow, and bone formation, both in vitro and in vivo. ${ }^{33}$ In previous studies, pores with sizes $>300 \mu \mathrm{m}$ were found to enhance osteogenesis, vascularization, and oxygenation. ${ }^{33,34}$ Accordingly, the structures of the pores of the proposed m_MCS/PCL/PBSu scaffold are suitable for use as a bone scaffold. Deligianni et al. mentioned that rough substrates enhance the initial attachment of OBs and mineralization processes. ${ }^{35}$ As shown in Fig. 1B, the surface of the $\mathrm{m}_{-} \mathrm{MCS} / \mathrm{PCL} / \mathrm{PBSu}$ scaffold was rougher than that of the $\mathrm{m} \_\mathrm{MCS} / \mathrm{PCL}$ scaffold. This may also affect the cell attachment and proliferation.

The XRD spectra of m_MCS, PCL, PBSu, m_MCS/PCL, and $\mathrm{m} \_$MCS/PCL/PBSu are shown in Fig. 2. The XRD pattern of the m_MCS (Fig. 2A) exhibits a broad peak at approximately $23^{\circ}$, which is typical of amorphous silicate materials. ${ }^{27,30}$ Also, the PCL exhibited prominent crystalline peaks at $2 \theta$ of $21.5^{\circ}, 22.1^{\circ}$, and $23.8^{\circ},{ }^{36}$ and the PBSu exhibited strong diffraction peaks at $19.6^{\circ}$ and $22.7^{\circ}$ (Fig. 2B). ${ }^{27}$ We found the characteristic peaks for both $\mathrm{m} \_$MCS and PCL in the m_MCS/PCL and m_MCS/PCL/ $\mathrm{PBSu}$, and the characteristic peaks of PBSu in m_MCS/PCL/ PBSu (Fig. 2C). These results confirm that the materials were uniformly mixed. Moreover, the diffraction peaks obtained from the m_MCS/PCL/PBSu composite were broader and less intense than those of $\mathrm{m} \_\mathrm{MCS} / \mathrm{PCL}$, which indicates that $\mathrm{m} \_\mathrm{MCS} / \mathrm{PCL} / \mathrm{PBSu}$ is less crystalline than m_MCS/PCL.

We evaluated the hydrophilic behavior of the m_MCS/PCL/ $\mathrm{PBSu}$ composites by measuring the contact angle of each material (Fig. 3A). The contact angle of the control material, PCL, with water was $74.17 \pm 1.5^{\circ}$. Moreover, the water contact angles fell significantly, to $66.59 \pm 3.1^{\circ}$ and $63.28 \pm 2.9^{\circ}$ for $\mathrm{m} \_\mathrm{MCS} / \mathrm{PCL}$ and $\mathrm{m} \_\mathrm{MCS} / \mathrm{PCL} / \mathrm{PBSu}$, respectively. Therefore, the hydrophilicity of the composite scaffold (i.e., m_MCS/PCL and $\mathrm{m} \_\mathrm{MCS} / \mathrm{PCL} / \mathrm{PBSu}$ ) is enhanced with respect to the PCL (control) scaffold, and the $\mathrm{m} \_\mathrm{MCS} / \mathrm{PCL} / \mathrm{PBSu}$ scaffold has the lowest contact angle. The hydrophilicity of the surface of the scaffold is a key element to consider when designing bone scaffolds, because it plays a decisive role during the initial interaction between the cells and the proteins in the bone. ${ }^{37}$ Fig. 3B shows the effect of the blending of each material on the compressive strength, with the value for the pure PCL scaffold taken as the control for comparison purposes. The compressive strengths of PCL, m_MCS/PCL and m_MCS/PCL/PBSu were approximately $15.9 \pm 1.7,14.1 \pm 2.1$ and $5.2 \pm 0.4 \mathrm{MPa}$, respectively, which is comparable to the compressive strength of cancellous bone $(2-20 \mathrm{MPa}){ }^{6}$ Although the compressive modulus of $\mathrm{m} \_\mathrm{MCS} / \mathrm{PCL} / \mathrm{PBSu}$ scaffold was significantly lower than that of the other experimental groups, these values were also significantly higher than that of the PBSu composite scaffold proposed in previous studies. ${ }^{38,39}$ 
A

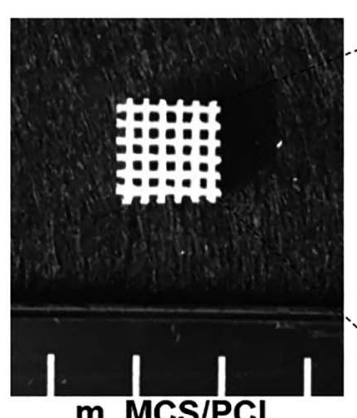
m_MCS/PCL

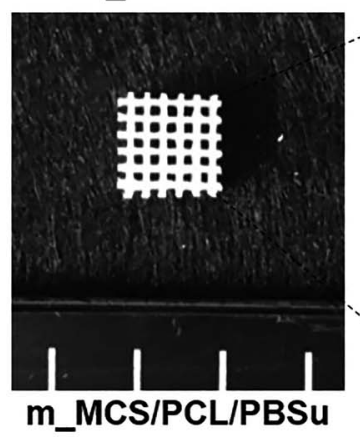

B

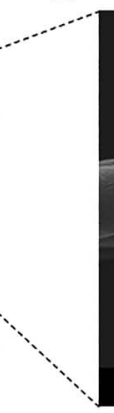

surface

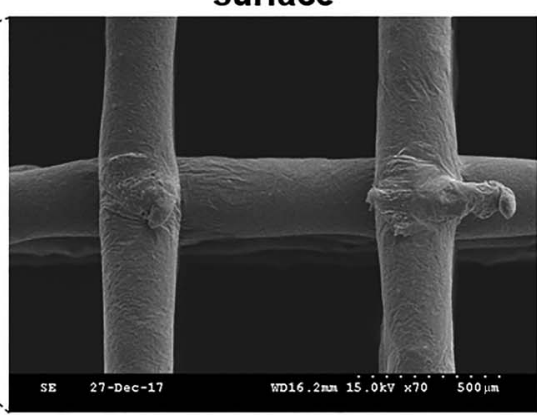

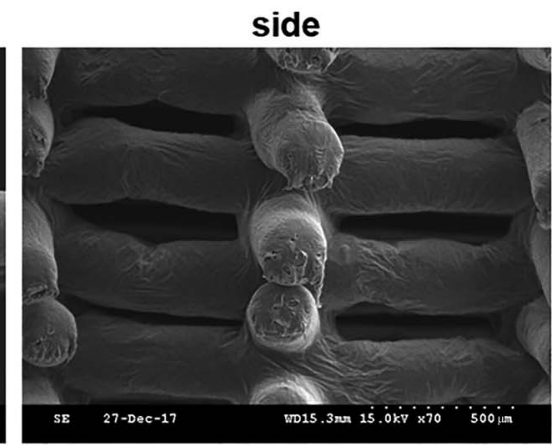
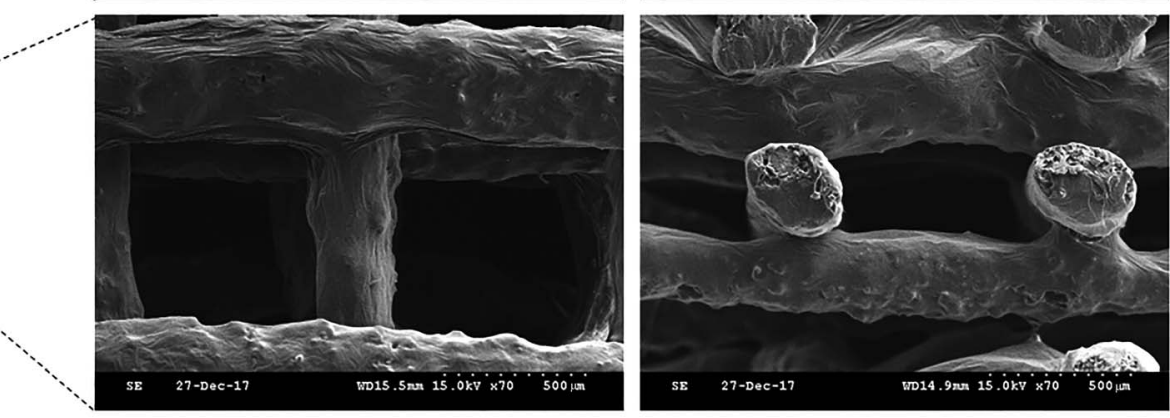

Fig. 1 Photographs (A) and SEM images (B) of m_MCS/PCL and m_MCS/PCL/PBSu scaffolds.
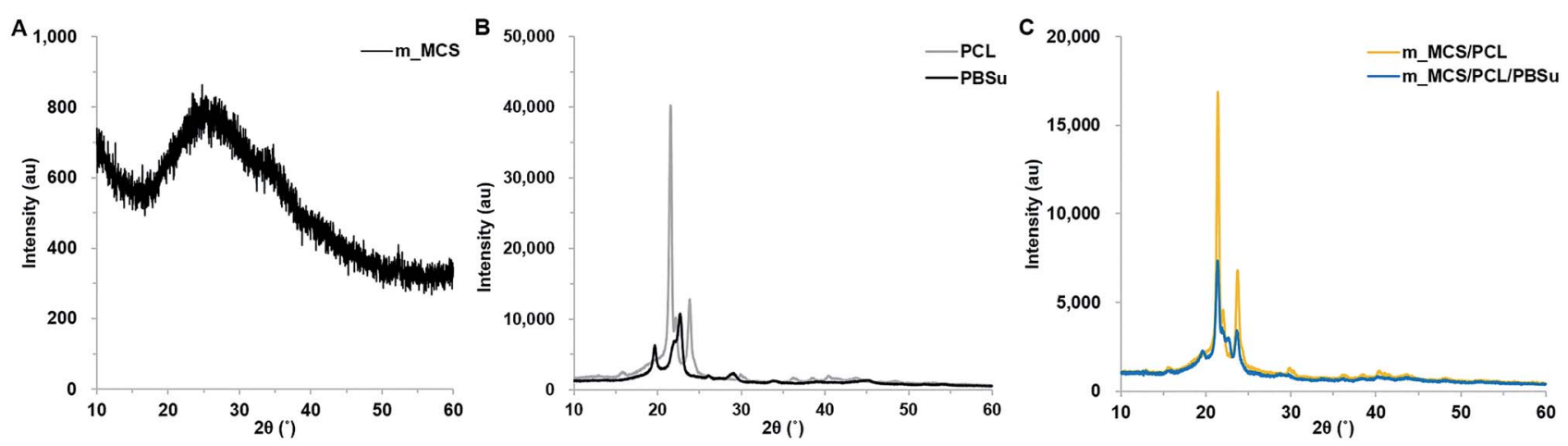

Fig. 2 XRD patterns of $m \_M C S(A), P C L, P B S u(B), m \_M C S / P C L$ composite, and m_MCS/PCL/PBSu composite (C).

\section{Water absorption and degradability of the $\mathbf{m} \_\mathbf{M C S} / \mathbf{P C L} / \mathbf{P B S u}$ scaffold}

The water absorptivity of the m_MCS/PCL and m_MCS/PCL/ PBSu scaffolds in SBF solution are shown in Fig. 4A. Both the $\mathrm{m} \_\mathrm{MCS} / \mathrm{PCL}$ and $\mathrm{m} \_\mathrm{MCS} / \mathrm{PCL} / \mathrm{PBSu}$ scaffolds continued to absorb water over time. The m_MCS/PCL/PBSu scaffold had higher water absorptivity, reaching up to $180.32 \%$ after 28 days. In contrast, the m_MCS/PCL scaffold had lower water absorptivity, absorbing only $108 \%$ by the end of the degradation experiment. These results indicate that both the m_MCS/PCL and $\mathrm{m} \_\mathrm{MCS} / \mathrm{PCL} / \mathrm{PBSu}$ scaffolds can absorb large amounts of water, with the water absorption ratio of the $\mathrm{m} \_\mathrm{MCS} / \mathrm{PCL} / \mathrm{PBSu}$ scaffold being significantly higher than that of the m_MCS/PCL scaffold. The physicochemical properties of biomaterials, such as the surface area, aggregation and absorption, play a crucial role in determining their potential interactions with biological systems after transplantation. ${ }^{40}$ Thus, these results confirm that the m_MCS/PCL/PBSu composite is suitable for use as a bone regeneration scaffold.

The proper degradability of biomaterials in a physiological environment is known to be an essential element of scaffoldbased bone tissue engineering. ${ }^{30}$ We assessed the degradation behavior by measuring the weight loss of the composite scaffolds, and the changes in the $\mathrm{pH}$ of the SBF solution after immersing the prepared scaffolds in SBF solution at $37{ }^{\circ} \mathrm{C}$ for different lengths of time. Fig. 4B shows the weight lost by the m_MCS/PCL and m_MCS/PCL/PBSu scaffolds. We confirmed that the weights lost by all of the composite scaffolds increased with incubation time, and the weight lost by the m_MCS/PCL/ PBSu scaffold was approximately $14.8 \%$ after soaking in SBF solution for 28 days, which was significantly higher than that of the $\mathrm{m} \_\mathrm{MCS} / \mathrm{PCL}$ scaffold, of $6.8 \%$. The $\mathrm{m} \_\mathrm{MCS} / \mathrm{PCL} / \mathrm{PBSu}$ 


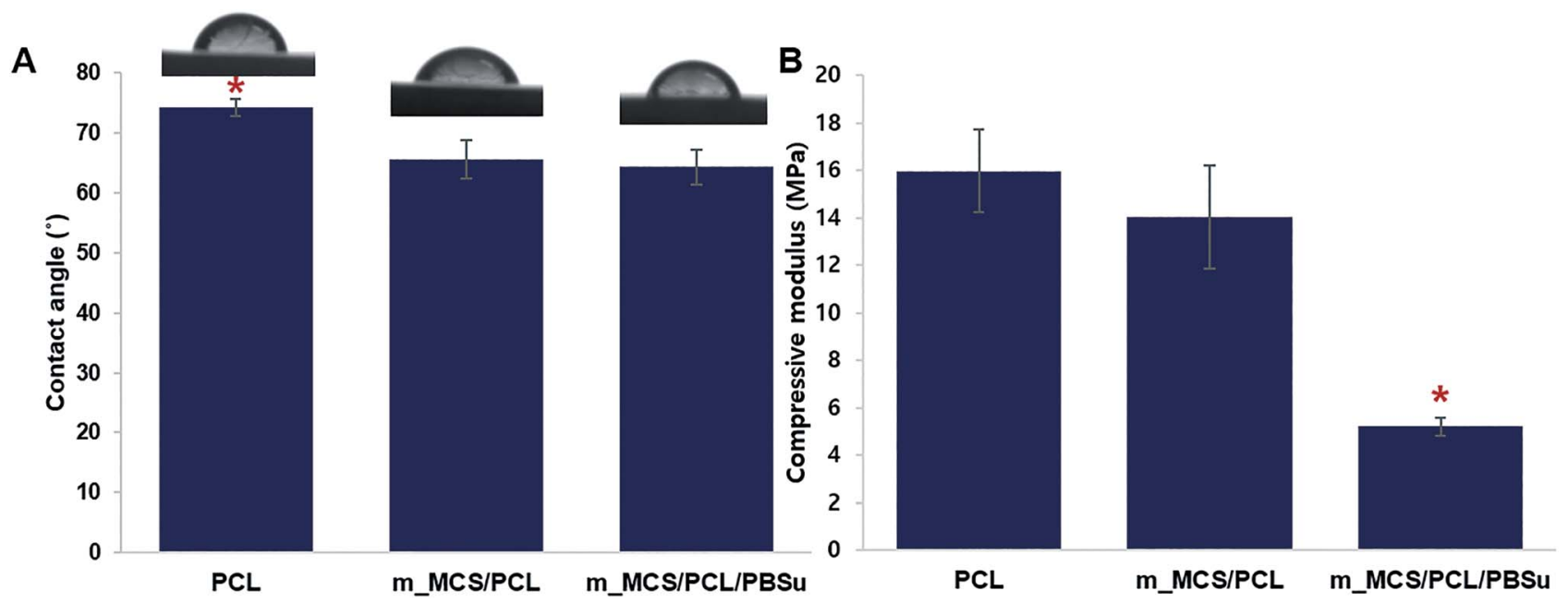

Fig. 3 Contact angle (A) and compressive modulus (B) of each scaffold $(n=5, * p<0.05)$.

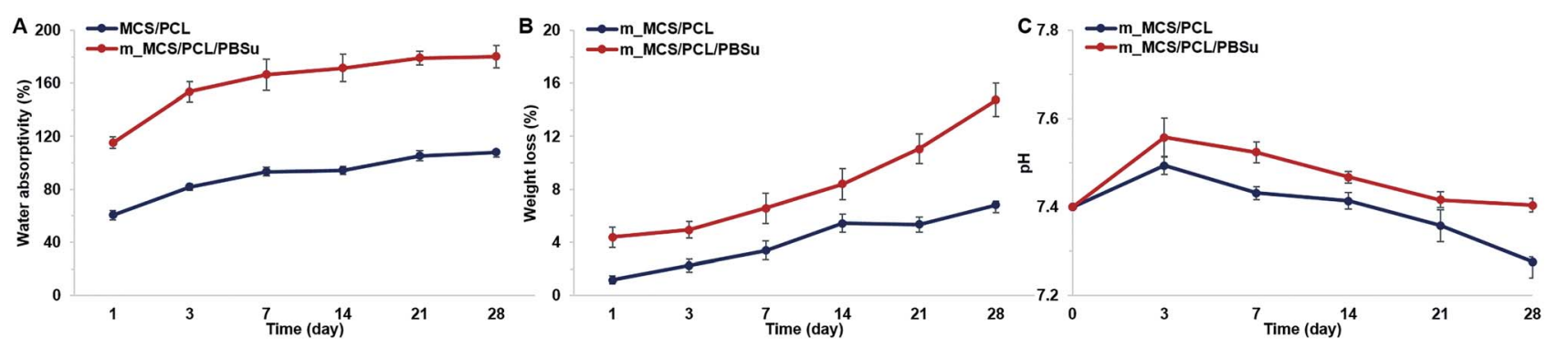

Fig. 4 Water absorptivity (A), weight loss (B) and pH level (C) of the solution for $m \_M C S / P C L$ and $m \_M C S / P C L / P B S u ~ s c a f f o l d s ~ a f t e r$ the samples had been immersed in DPBS for different times (1, 3, 4, 14, 21, and 28 days).

scaffold degraded steadily over time, with a weight loss rate of approximately $2-3.5 \%$ per week. The biomaterials used for bone tissue engineering should be degradable when they are implanted in vivo so that they can be replaced by new bone. Also, Bryant and Anseth demonstrated that enhanced biodegradability of biomaterials can affect the cell proliferation and ECM distribution in vitro. ${ }^{41}$ Therefore, the constant degradation rate and enhanced degradability of the $\mathrm{m} \_\mathrm{MCS} / \mathrm{PCL} / \mathrm{PBSu}$ scaffold compared to the m_MCS/PCL scaffold confirms its suitability for applications as a scaffold for bone regeneration.

Fig. 4C shows the changes in $\mathrm{pH}$ value of the solution after immersing the $\mathrm{m} \_\mathrm{MCS} / \mathrm{PCL}$ and $\mathrm{m} \_\mathrm{MCS} / \mathrm{PCL} / \mathrm{PBSu}$ scaffolds for different lengths of time. In the case of the m_MCS/PCL composite scaffold, the $\mathrm{pH}$ value of the solution increased gradually until day 3 , up to 7.49 , but then gradually decreased to 7.29 over time. In the case of the m_MCS/PCL/PBSu composite scaffold, the $\mathrm{pH}$ of the solution increased over 3 days, from its initial value of 7.40 up to 7.56 , then gradually decreased to 7.4 by the end of the whole degradation period. These results indicated that the addition of PBSu to the m_MCS/PCL composite increase the $\mathrm{pH}$ value of the solution, suggesting that the addition of $\mathrm{PBSu}$ to the composite could be used to control the $\mathrm{pH}$ level when soaking the scaffold in the SBF solution.

\section{Bioactivity of m_MCS/PCL/PBSu scaffold}

The changes in concentrations of $\mathrm{Ca}, \mathrm{Si}, \mathrm{Mg}$, and $\mathrm{P}$ ions in the SBF solution after soaking the composite scaffolds for different lengths of time $(0,1,3,5,7$, and 10 days) are shown in Fig. 5. The concentrations of $\mathrm{Ca}$ and $\mathrm{P}$ ions tended to decrease with time (Fig. 5A). More specifically, the concentration of $\mathrm{Ca}$ ions decreased slightly until day 3 , but decreased sharply from day 3 to day 10, especially in the $\mathrm{m} \_\mathrm{MCS} / \mathrm{PCL} / \mathrm{PBSu}$ scaffold compared to the $\mathrm{m}$-MCS/PCL scaffold. In addition, the concentration of $\mathrm{P}$ ions decreased continuously in both composite scaffolds, but significantly more so in the m_MCS/ PCL/PBSu scaffold than in the m_MCS/PCL scaffold. Many studies have indicated that the ionic dissolutions of the products from inorganic materials are important for understanding the behavior of these materials, both in vitro and in vivo. ${ }^{37}$ Since the main components of human bone apatite are calcium and phosphorus $\left(\mathrm{Ca}_{10}\left(\mathrm{PO}_{4} \mathrm{CO}_{3}\right)_{6} \mathrm{OH}_{2}\right)$, both $\mathrm{Ca}$ and $\mathrm{P}$ ions are essential for bone formation and resorption. In many studies, the decrease in $\mathrm{Ca}$ and $\mathrm{P}$ ion concentrations in SBF over time is considered to be an indirect indicator of an apatite precipitation reaction. ${ }^{27,30,36}$ Therefore, these results suggest that the m_MCS/PCL/PBSu scaffold exhibits excellent bioactivity, and hence provides a more appropriate environment for the 

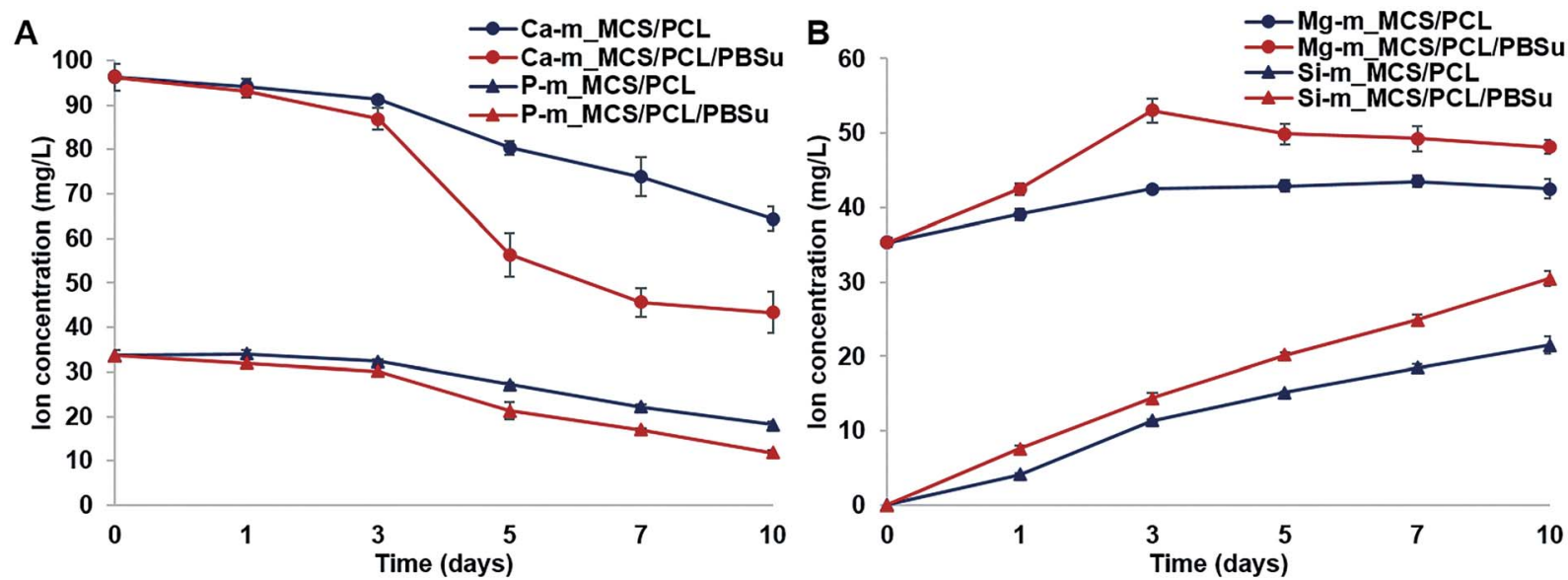

Fig. 5 Variation in the concentrations of $\mathrm{Ca}, \mathrm{P}(\mathrm{A}), \mathrm{Mg}, \mathrm{Si}(\mathrm{B})$ ions in SBF solution after immersing the $\mathrm{m} \_M C S / P C L$ and $\mathrm{m} \_M C S / P C L / P B S u$ scaffolds for different length of time.

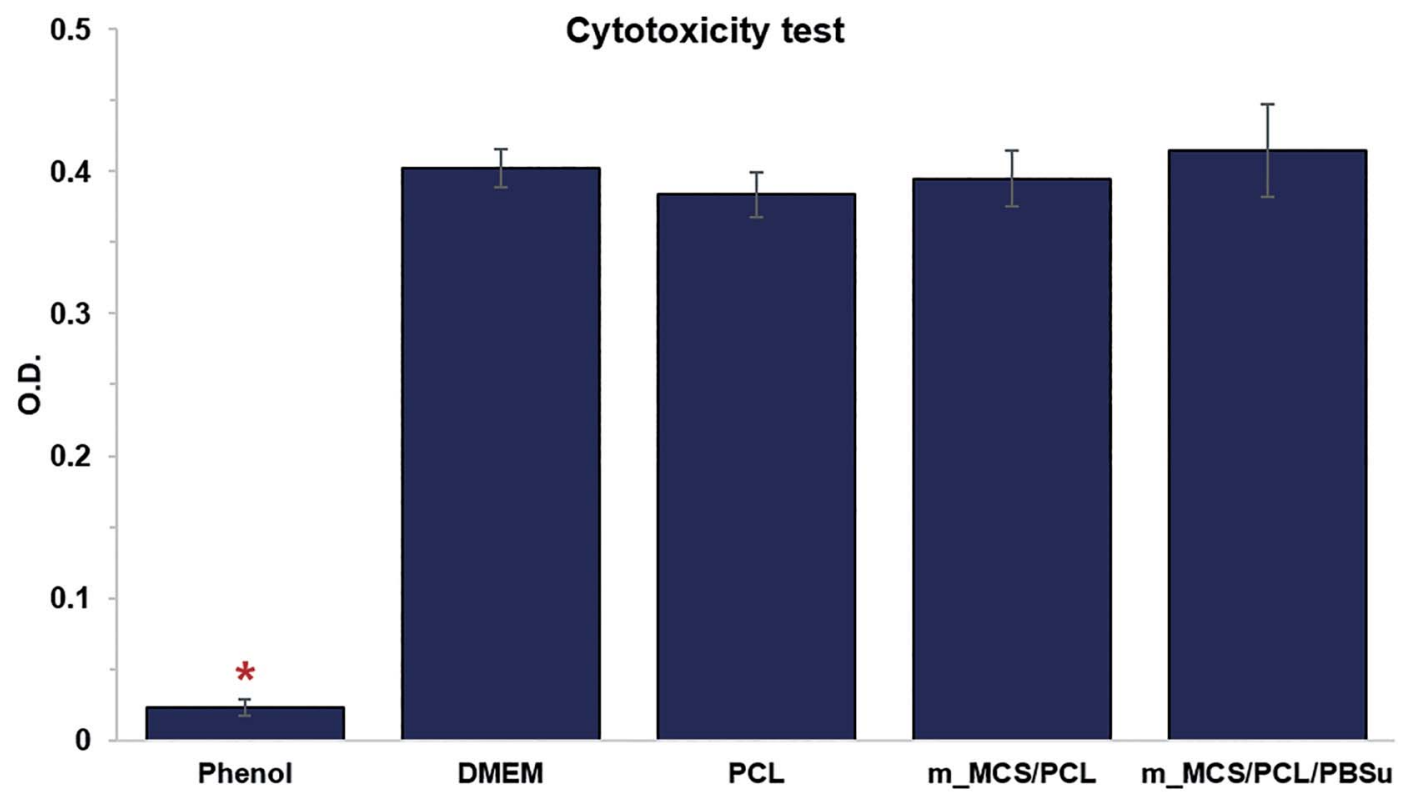

Fig. 6 Cytotoxicity evaluation of composite scaffold with L929 mouse fibroblast-like cells in comparison with the negative (DMEM alone and PCL extracts) and positive (diluted phenol) controls after $24 \mathrm{~h}(n=6, * p<0.05)$.

formation of chemical bonds between native bone and the scaffold through the apatite layer than m_MCS/PCL scaffold.

In contrast to the decrease in the concentrations of $\mathrm{Ca}$ and $\mathrm{P}$ ions, the concentrations of $\mathrm{Mg}$ and $\mathrm{Si}$ ions increased consistently during the mineralization process (Fig. 5B). We also confirmed that the concentrations of $\mathrm{Mg}$ and $\mathrm{Si}$ ions increased to a significantly greater degree in the $\mathrm{m} \_\mathrm{MCS} / \mathrm{PCL} / \mathrm{PBSu}$ scaffold than in the $\mathrm{m} \_$MCS/PCL scaffold. Several studies have shown that $\mathrm{Mg}$ ions play an important role in regulating cell behavior, including DNA and protein synthesis, cell adhesion and the $\mathrm{Mg}$ conduction channels. ${ }^{42,43}$ Also, many studies have reported that $\mathrm{Si}$ ions affect the osteogenic differentiation, induction of new bone formation and mineralization. ${ }^{44}$ Based on these results, we can explain the excellent cell adhesion of
MSCs and induction of osteogenic differentiation in the m_MCS/PCL/PBSu scaffold (Fig. 9-11).

\section{Cytotoxicity of $\mathbf{m} \_$MCS/PCL/PBSu scaffold}

We performed in vitro cytotoxicity tests to assess the cytotoxicity of each material in terms of ISO 10993-12 and ISO 10993-5. In Fig. 6, we show the absorbance obtained from an MTT assay of L929 cells cultured with each extract media in comparison to those cultured with phenol (positive control), and DMEM and PCL (negative control). These results confirmed that there were no significant differences between the negative control groups (PCL and DMEM) and the groups cultured with extracts from the $\mathrm{m} \_\mathrm{MCS} / \mathrm{PCL}$ and $\mathrm{m} \_\mathrm{MCS} / \mathrm{PCL} / \mathrm{PBSu}$ scaffolds. As expected, 


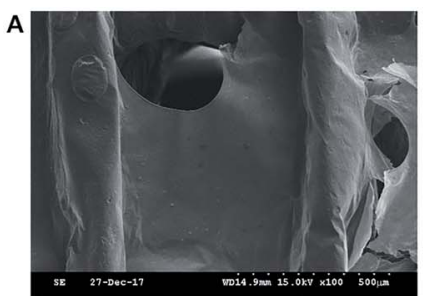
m_MCS/PCL

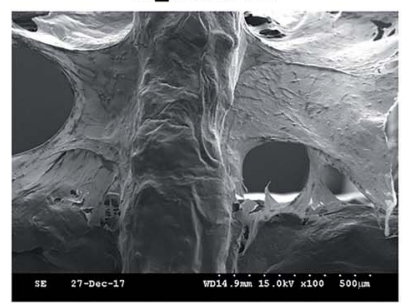

m_MCS/PCL/PBSu

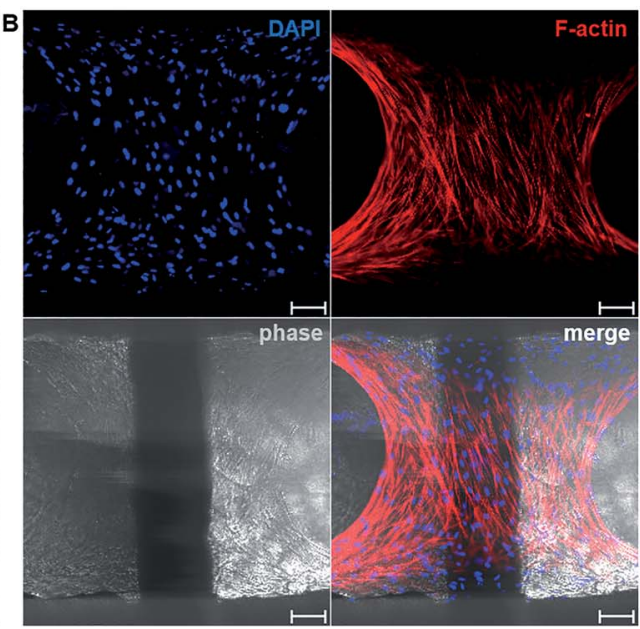

m_MCS/PCL

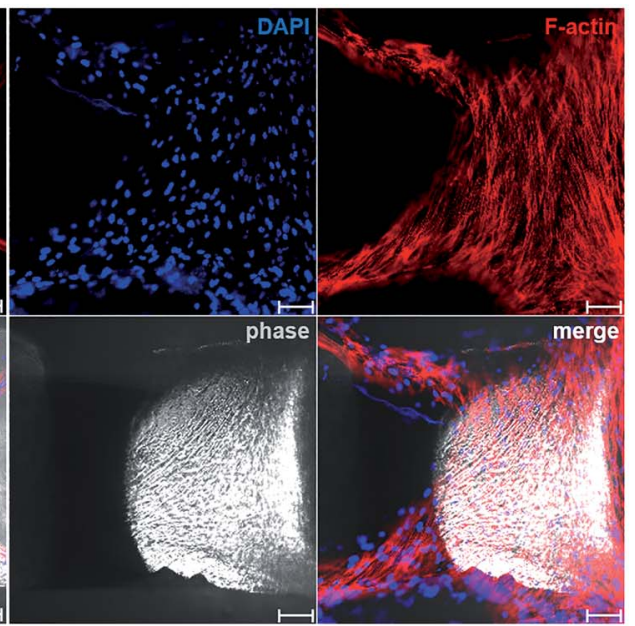

m_MCS/PCL/PBSu

Fig. 7 SEM images (A) and fluorescence microscope images (B) of MSCs cultured on the two types of scaffolds from day 7. The nuclei are colored blue (DAPI) and the F-actin is colored red (rhodamine phalloidin), ( $\times 100$, scale bar = (A) $500 \mu \mathrm{m}$ and (B) $100 \mu \mathrm{m}$, respectively).

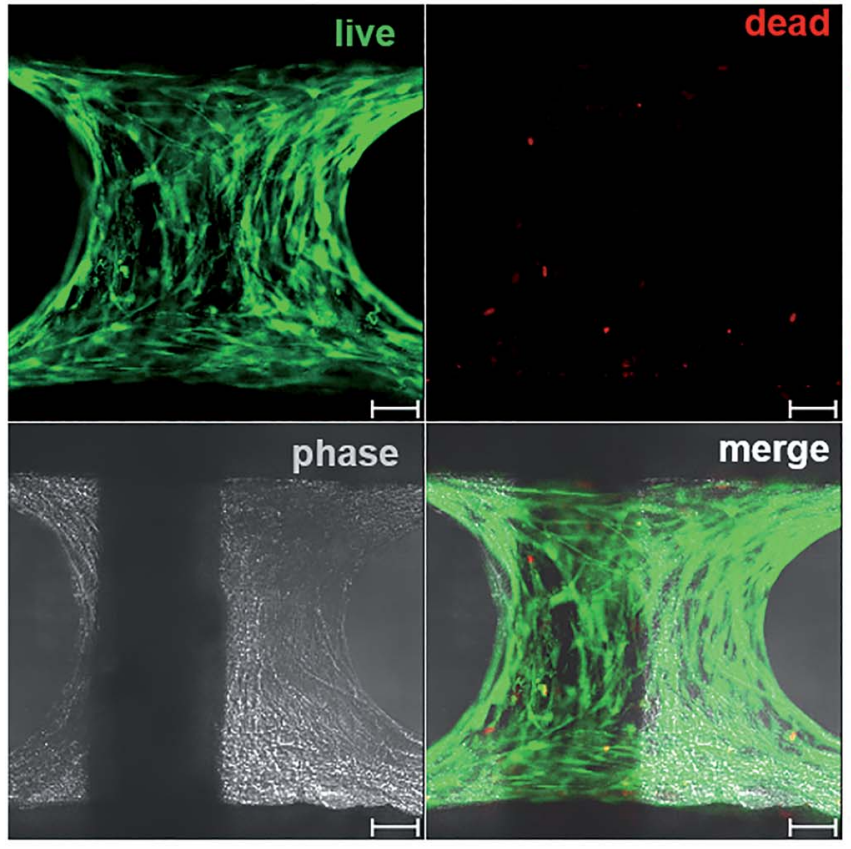

m_MCS/PCL

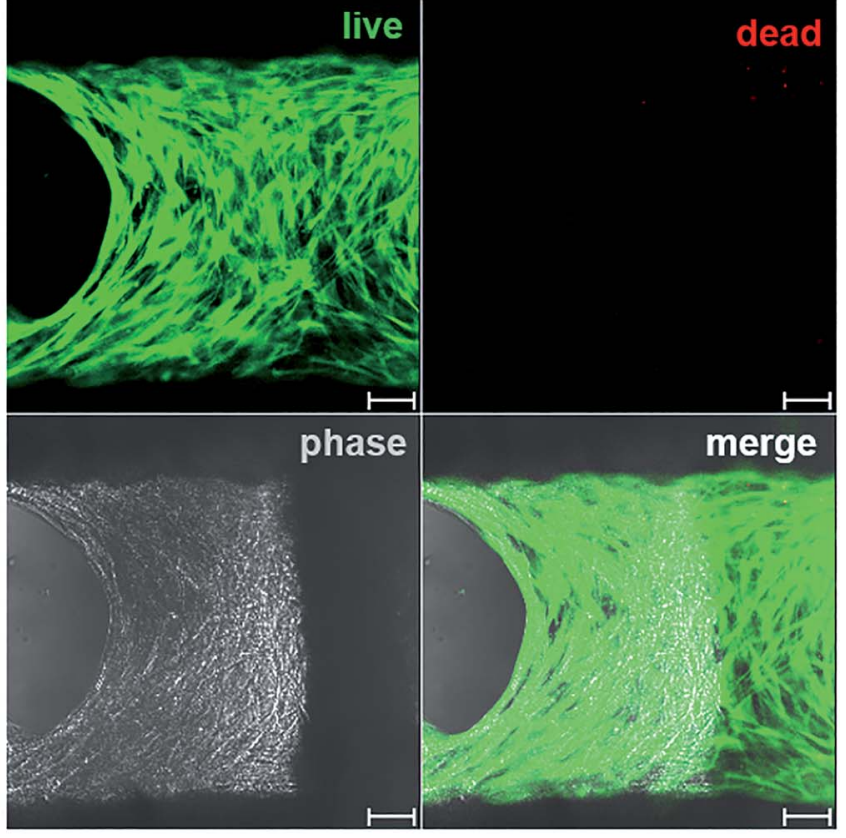

m_MCS/PCL/PBSu

Fig. 8 Live-dead cell staining images of MSCs cultured on each scaffold on day 7. Living cells were detected as green fluorescence and dead cells were detected as red fluorescence $(\times 100$, scale bar $=100 \mu \mathrm{m})$.

$1 \%$ phenol (positive control) showed significantly lower O.D. values than the other groups $(n \geq 5, p<0.05)$. These results clearly demonstrate that the m_MCS, PCL, and PBSu constituents of the scaffold are not cytotoxic.

Morphology, viability and proliferation of MSCs on scaffolds

The SEM microscopy images show the morphological features of MSCs cultured on $\mathrm{m} \_\mathrm{MCS} / \mathrm{PCL}$ and $\mathrm{m} \_\mathrm{MCS} / \mathrm{PCL} / \mathrm{PBSu}$ scaffolds for 7 days (Fig. 7A). As expected, the cells were spread well over the surface of the scaffold and formed confluent cell layers in intimate contact with the surfaces of both composites. The cells of both composite scaffolds formed bridges over the strands, filled the scaffold pores, and maintained physical contact with each other. These results are consistent with the confocal images presented in this paper. Fig. 7B shows a confocal microscope image of the stained nuclei (blue) and Factin (red) on the surfaces of both composite scaffolds after culturing the cells for 7 days. The cells began to fill in the interconnected pore structures after spreading over the entirety 


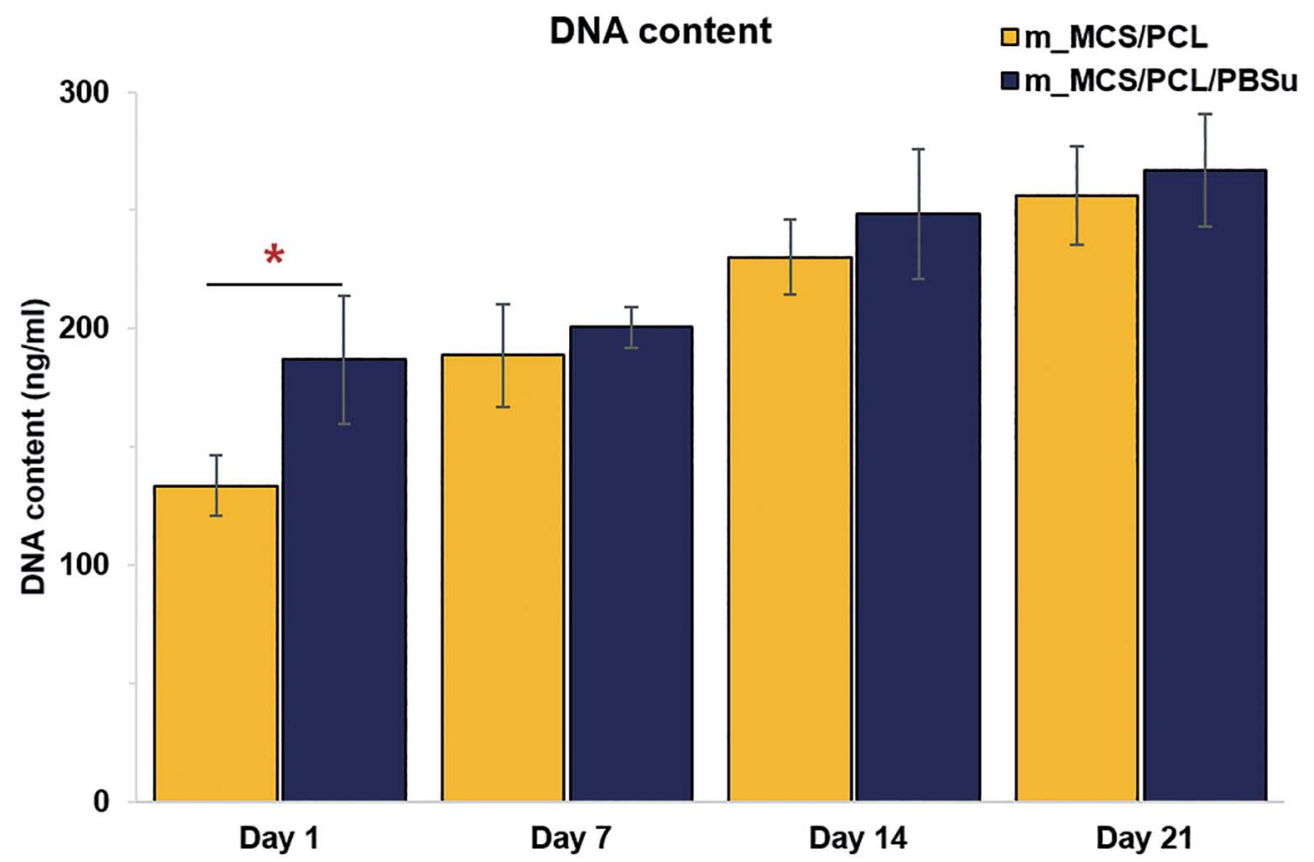

Fig. 9 DNA content reflecting the proliferation of MSCs cultured in osteogenic media on the two types of scaffolds for up to 21 days $(n=6$, * $p<$ 0.05).

\section{ALP/DNA}

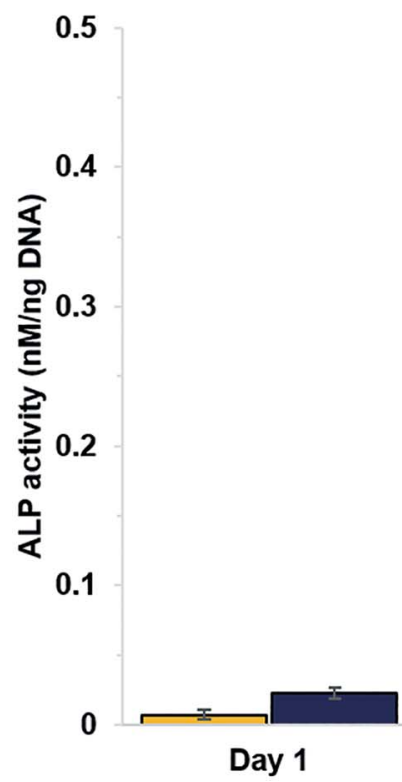

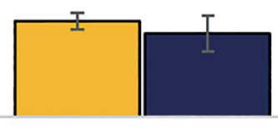

Day 7
口m_MCS/PCL

am_MCS/PCL/PBSu

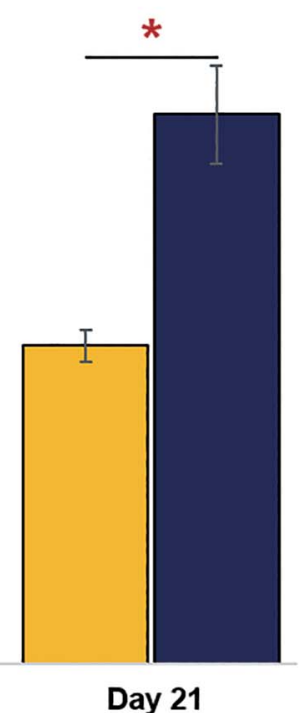

Fig. 10 Normalized ALP activity of MSCs on each scaffold for up to 21 days ( $n=6,{ }^{*} p<0.05$ ).

of the strands of the scaffold. These images alone did not reveal any significant differences between the two composite scaffolds. We also performed live/dead viability assays to confirm the viability of the MSCs on each composite scaffold (Fig. 8). As expected, the number of dead cells (red) was extremely small in comparison to the number of live cells (green), and the ratios were similar for both scaffolds. These results are consistent with previous cytotoxicity results (Fig. 6) and further confirm that none of the composite scaffolds are toxic to cells.

The results for the proliferation of cells cultured in each scaffold for 21 days are shown in Fig. 9. The m_MCS/PCL/PBSu scaffolds had significantly higher DNA contents, and therefore better cell attachment, than the m_MCS/PCL scaffolds by day 1 $(n=6, p<0.05)$. We observed similar results with both 

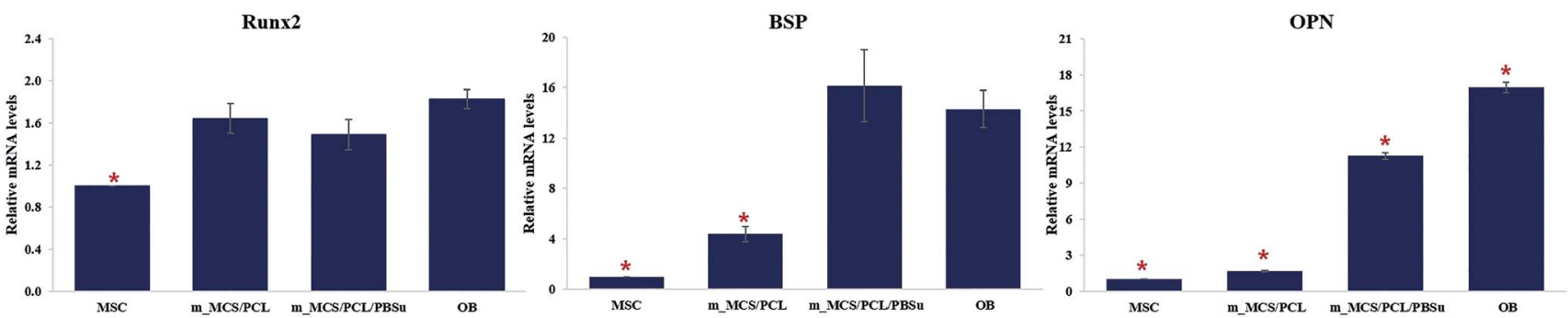

Fig. 11 Expression levels of the osteogenic-markers, such as RUNX2, BSP, and OPN, in MSCs cultured on each scaffold on day 21.

scaffolds, with their cell proliferation increasing markedly with culture time.

\section{Osteogenic differentiation of MSCs on scaffolds}

We assessed the differentiation of the MSCs cultured on $\mathrm{m} \_\mathrm{MCS} / \mathrm{PCL}$ and $\mathrm{m} \_\mathrm{MCS} / \mathrm{PCL} / \mathrm{PBSu}$ scaffolds in terms of their ALP activities, normalized with respect to their DNA contents, after culturing for $1,7,14$, and 21 days (Fig. 10). ALP is a known marker of potential osteogenic differentiation and bone formation activity, and is often evaluated during in vitro experiments. ${ }^{45}$ The ALP activity increased steadily with time and we did not observe any significant differences between the m_MCS/ PCL and $\mathrm{m} \_\mathrm{MCS} / \mathrm{PCL} / \mathrm{PBSu}$ composites until day 14 . The maximum ALP activity was reached by day 21 and was significantly greater in the $\mathrm{m} \_\mathrm{MCS} / \mathrm{PCL} / \mathrm{PBSu}$ scaffold than in the m_MCS/PCL scaffold $(n=6, p<0.05)$.

We also carried out qRT-PCR analysis on $\mathrm{m} \_$MCS/PCL and m_MCS/PCL/PBSu scaffolds so that we could quantitatively evaluate the osteogenic-related gene expression. We treated osteogenic gene expression as a biomarker of bone turnover, with RUNX2 characterizing the early stages, and BSP and OPN as markers for the middle to late stages. We harvested MSCs cultured on each scaffold after culturing for 21 days, then assessed their relative gene expression levels (Fig. 11). Using MSCs (passage \#3) and OBs (passage \#2) as negative and positive controls, respectively, we found the expression levels of osteogenic-related genes to be significantly higher in cells cultured for 21 days on the composite scaffolds than the MSCs (i.e., the negative control). The expression levels of the BSP and OPN genes in the groups cultured on the composite scaffold were significantly higher in the $\mathrm{m} \_\mathrm{MCS} / \mathrm{PCL} / \mathrm{PBSu}$ group than in the $\mathrm{m} \_\mathrm{MCS} / \mathrm{PCL}$ group. Moreover, the expression of osteogenic genes in the $\mathrm{m} \_\mathrm{MCS} / \mathrm{PCL} / \mathrm{PBSu}$ group was similar to that of fully developed OBs. Many studies have shown that $\mathrm{Mg}$ and $\mathrm{Si}$ ions can be used to improve osteogenic differentiation, and $\mathrm{Si}$ ions enhance the ability of OBs to produce type I collagen, which promotes cell differentiation. ${ }^{42-44}$ In another study, the release of high levels of Si ions produced significant osteogenic effects, and increased extracellular calcium was proved to stimulate OB-like cells. ${ }^{46}$ The results of our assessment of the osteogenic differentiation (Fig. 10 and 11) are in agreement with those of previous studies, and consistent with the results of previous evaluations of the bioactivity (Fig. 5). In other words, the increased ALP activity and expression of osteogenic-related markers observed in this study was probably caused by the $\mathrm{m} \_\mathrm{MCS} / \mathrm{PCL} / \mathrm{PBSu}$ composite, indicating that the $\mathrm{Mg}$ and $\mathrm{Si}$ ions may be responsible for improving the osteogenic differentiation.

\section{Conclusions}

In this study, we describe a new composite based on m_MCS, PCL and PBSu that can potentially be used for bone tissue regeneration. Moreover, we applied an RP technique to achieve control over the fabrication of the $\mathrm{m} \_\mathrm{MCS} / \mathrm{PCL}$ and $\mathrm{m} \_\mathrm{MCS} /$ PCL/PBSu scaffolds and obtain well-interconnected pores, and then conducted a comparative study to characterize the two composites and evaluate them osteogenically. Our results demonstrated that $\mathrm{m} \_\mathrm{MCS} / \mathrm{PCL} / \mathrm{PBSu}$ scaffolds have better water absorptivity, degradability, and apatite formation abilities than $\mathrm{m} \_$MCS/PCL scaffolds. In addition, the initial cell attachment, ALP activity and osteogenic gene expression of the MSCs were significantly higher in the case of the $\mathrm{m} \_\mathrm{MCS} / \mathrm{PCL} / \mathrm{PBSu}$ scaffolds than for the m_MCS/PCL scaffold, indicating that the $\mathrm{m} \_\mathrm{MCS} / \mathrm{PCL} / \mathrm{PBSu}$ scaffolds had significantly better cytocompatibility and osteogenic potential than the $\mathrm{m} \_\mathrm{MCS} / \mathrm{PCL}$ scaffold. However, further studies are required to confirm the optimal composition for obtaining good mechanical properties.

In summary, the $\mathrm{m} \_\mathrm{MCS} / \mathrm{PCL} / \mathrm{PBSu}$ composite scaffolds fabricated by the RP technique exhibited superior biocompatibility, degradability, bioactivity, cytocompatibility and osteogenic potential than the scaffolds produced by conventional methods. Hence, these scaffolds are a promising candidate for cell-based bone tissue engineering.

\section{Conflicts of interest}

The authors declare that there is no conflict of interest regarding the publication of this article.

\section{Acknowledgements}

This work was supported by the National Research Foundation of Korea (NRF) Grant (NRF-2015M3A9B6073643) and by a grant of the Korea Health Technology R\&D Project through the KHIDI (HI16C0362, the Ministry of Health \& Welfare, ROK). 


\section{References}

1 A. S. Greenwald, S. D. Boden, V. M. Goldberg, Y. Khan, C. T. Laurencin and R. N. Rosier, J. Bone Jt. Surg., Am. Vol., 2001, 83, 98-103.

2 E. Chiarello, M. Cadossi, G. Tedesco, P. Capra, C. Calamelli, A. Shehu and S. Giannini, Aging: Clin. Exp. Res., 2013, 25, 101-103.

3 V. M. Goldberg and S. Stevenson, Orthopedics, 1994, 17, 809821.

4 R. R. Betz, Orthopedics, 2002, 25, 561-570.

5 R. Dimitriou, E. Jones, D. McGonagle and P. V. Giannoudis, BMC Med., 2011, 9, 66.

6 S. Bose, M. Roy and A. Bandyopadhyay, Trends Biotechnol., 2012, 30, 546-554.

7 J. M. Holzwarth and P. X. Ma, Biomaterials, 2011, 32, 96229629.

8 M. N. Rahaman, D. E. Day, B. S. Bal, Q. Fu, S. B. Jung, L. F. Bonewald and A. P. Tomsia, Acta Biomater., 2011, 7, 2355-2373.

9 Y. Zhu, C. Gao and J. Shen, Biomaterials, 2002, 23, 48894895.

10 F. Hajiali, S. Tajbakhsh and A. Shojaei, Polym. Rev., 2018, 58, 164-207.

11 H. Li, J. Chang, A. Cao and J. Wang, Macromol. Biosci., 2005, 5, 433-440.

12 H. Wang, J. Ji, W. Zhang, Y. Zhang, J. Jiang, Z. Wu, et al., Acta Biomater., 2009, 5, 279-287.

13 P. Ngamviriyavong, S. Patntirapong, W. Janvikul, S. Arphavasin, P. Meesap and W. Singhatanadgit, Compos. Interfaces, 2014, 21, 431-441.

14 D. F. Coutinho, I. H. Pashkuleva, C. M. Alves, A. P. Marques, N. M. Neves and R. L. Reis, Biomacromolecules, 2008, 9, 11391145.

15 H. Wang, J. Ji, W. Zhang, W. Wang, Y. Zhang, Z. Wu, et al., Acta Biomater., 2010, 6, 154-159.

16 S. A. Park, S. H. Lee and W. D. Kim, Bioprocess Biosyst. Eng., 2011, 34, 505-513.

17 S. I. Roohani-Esfahani, S. Nouri-Khorasani, Z. F. Lu, R. C. Appleyard and H. Zreiqat, Acta Biomater., 2011, 7, 1307-1318.

18 V. Maquet, A. R. Boccaccini, L. Pravata, I. Notingher and R. Jérôme, Biomaterials, 2004, 25, 4185-4194.

19 K. Rezwan, Q. Z. Chen, J. J. Blaker and A. R. Boccaccini, Biomaterials, 2006, 27, 3413-3431.

20 X. Li, J. Shi, X. Dong, L. Zhang and H. Zeng, J. Biomed. Mater. Res., Part A, 2008, 84, 84-91.

21 M. Zhu, J. Zhang, S. Zhao and Y. Zhu, J. Mater. Sci., 2016, 51, 836-844.

22 C. Wu, Y. Zhou, W. Fan, P. Han, J. Chang, J. Yuen, et al., Biomaterials, 2012, 33, 2076-2085.
23 J. Zhang, S. Zhao, Y. Zhu, Y. Huang, M. Zhu, C. Tao and C. Zhang, Acta Biomater., 2014, 10, 2269-2281.

24 S. Fu, W. Liu, S. Liu, S. Zhao and Y. Zhu, Sci. Technol. Adv. Mater., 2018, 19, 495-506.

25 Y. Zhu, M. Zhu, X. He, J. Zhang and C. Tao, Acta Biomater., 2013, 9, 6723-6731.

26 J. Lu, J. Wei, Q. Gan, X. Lu, X. Hou, J. Song and C. Liu, Microporous Mesoporous Mater., 2012, 163, 221-228.

27 Y. Ding, S. Tang, B. Yu, Y. Yan, H. Li, J. Wei and J. Su, J. R. Soc., Interface, 2015, 12, 20150779.

28 D. W. Hutmacher, J. Biomater. Sci., Polym. Ed., 2001, 12, 107124.

29 S. M. Peltola, F. P. Melchels, D. W. Grijpma and M. Kellomäki, Ann. Med., 2008, 40, 268-280.

30 X. Zhang, C. Zhang, W. Xu, B. Zhong, F. Lin, J. Zhang, et al., Int. J. Nanomed., 2015, 10, 6699-6708.

31 T. Kokubo and H. Takadama, Biomaterials, 2006, 27, 29072915.

32 S. J. Heo, S. E. Kim, J. Wei, Y. T. Hyun, H. S. Yun, D. H. Kim, et al., J. Biomed. Mater. Res., Part A, 2009, 89, 108-116.

33 V. Karageorgiou and D. Kaplan, Biomaterials, 2005, 26, 54745491.

34 H. E. Götz, M. Müller, A. Emmel, U. Holzwarth, R. G. Erben and R. Stangl, Biomaterials, 2004, 25, 4057-4064.

35 D. D. Deligianni, N. D. Katsala, P. G. Koutsoukos and Y. F. Missirlis, Biomaterials, 2001, 22, 87-96.

36 K. Y. Tsai, H. Y. Lin, Y. W. Chen, C. Y. Lin, T. T. Hsu and C. T. Kao, Materials, 2017, 10, E65.

37 D. E. MacDonald, N. Deo, B. Markovic, M. Stranick and P. Somasundaran, Biomaterials, 2002, 23, 1269-1279.

38 J. T. Oliveira, V. M. Correlo, P. C. Sol, A. R. Costa-Pinto, P. B. Malafaya, A. J. Salgado, et al., Tissue Eng., Part A, 2008, 14, 1651-1661.

39 Z. Wu, K. Zheng, J. Zhang, T. Tang, H. Guo, A. R. Boccacini and J. Wei, J. Mater. Chem. B, 2016, 4, 7974-7988.

40 S. Lee, H. S. Yun and S. H. Kim, Biomaterials, 2011, 32, 94349443.

41 S. J. Bryant and K. S. Anseth, J. Biomed. Mater. Res., 2002, 59, 63-72.

42 A. Hoppe, N. S. Güldal and A. R. Boccaccini, Biomaterials, 2011, 32, 2757-2774.

43 E. Abed and R. Moreau, Am. J. Physiol.: Cell Physiol., 2009, 297, C360-C368.

44 Y. H. Lin, Y. C. Chiu, Y. F. Shen, Y. A. Wu and M. Y. Shie, J. Mater. Sci.: Mater. Med., 2017, 29, 11.

45 A. Nakamura, Y. Dohi, M. Akahane, H. Ohgushi, H. Nakajima, H. Funaoka and Y. Takakura, Tissue Eng., Part C, 2009, 15, 169-180.

46 M. Y. Shie, S. J. Ding and H. C. Chang, Acta Biomater., 2011, 7, 2604-2614. 